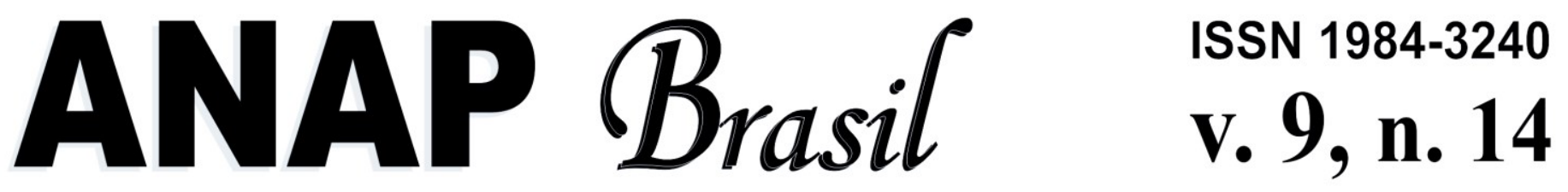

\title{
EDUCAÇÃO DO CAMPO E SUSTENTABILIDADE: UMA EXPERIÊNCIA DO PRONERA
}

Education of the countryside and sustainability: an experience of the PRONERA

La educación del campo y la sostenibilidad: una experiencia de PRONERA

Rodrigo Simão Camacho

Doutor em Geografia pela FCT-UNESP. Professor do Curso de Licenciatura em Educação do Campo (LEDUC) na Faculdade Intercultural Indígena (FAIND) da Universidade Federal da Grande Dourados (UFGD).

E-mail: rogeo@ymail.com 


\section{ANAP

Resumo: No tocante a sustentabilidade, a agricultura familiar camponesa desempenha um papel importante na produção de alimentos para o consumo interno e defende práticas agroecológicas. A luta camponesa pela terra por meio dos movimentos sociais camponeses desencadeou a construção teóricapolítica-ideológica de um modelo de educação fundado em princípios e práticas sustentáveis de produção e organização social. Dessa forma, o principal objetivo deste artigo é analisar a experiência de integração entre educação e sustentabilidade, no Programa Nacional de Educação na Reforma Agrária (PRONERA). Para alcançar este objetivo, uma pesquisa com um questionário semi-estruturado foi realizado entre professores, alunos, monitores e coordenadores do Curso Especial de Graduação em Geografia oferecido pelo PRONERA. As pesquisas mostraram que os cursos estão discutindo os conceitos de sustentabilidade entre os camponeses.

Palavras-chave: Educação do Campo, Sustentabilidade, PRONERA.

Abstract: With respect sustainability, the peasant family agriculture plays an important role in food production for domestic consumption and defends agro-ecological practices. The peasant struggle for land by peasant social movements unleashed theoretical-political-ideological construction of an educational model based on sustainable principles and practices of production and social organization. Thus, the main objective of this paper is to analyze the experience of integration between education and sustainability, in the National Education Program in Agrarian Reform (PRONERA). To accomplish this, a survey of a semi-structured questionnaire was conducted among teachers, students, monitors and coordinators of the Special Course Undergraduate Geography offered by PRONERA. Research has shown that the courses are discussing the concepts of sustainability among the peasants.

Keywords: Rural Education, Sustainability, PRONERA.

Resumen: Con respecto a la sostenibilidad, la agricultura familiar campesina desempeña un papel importante en la producción de alimentos para el consumo interno y defiende las prácticas agroecológicas. La lucha campesina por la tierra por los movimientos sociales campesinos provocó la construcción teórico-político-ideológica de un modelo educativo basado en los principios y prácticas de producción y organización social sostenibles. Por lo tanto, el objetivo principal de este trabajo es analizar la experiencia de la integración entre la educación y la sostenibilidad en el Programa Nacional de Educación en la Reforma Agraria (PRONERA). Para lograr esto, una encuesta de un cuestionario semiestructurado se llevó a cabo entre profesores, alumnos, monitores y coordinadores del Curso Especial de Pregrado en Geografía ofrecidos por PRONERA. La investigación ha demostrado que los cursos están discutiendo los conceptos de sostenibilidad entre los campesinos.

Palabras clave: Educación del Campo, Sustentabilidad, PRONERA. 


\section{INTRODUÇÃO}

Existe uma desigualdade educacional no tocante aos moradores das áreas rurais brasileiras. A fim de ser combatida, essa desigualdade exige políticas específicas destinadas a melhorar a educação praticada no campo. Estas políticas têm de ter em conta as particularidades dos sujeitos do campo, bem como, o seu modo de vida.

A Educação do Campo é sustentável, pois permite o desenvolvimento territorial entre os camponeses. A Educação do Campo emerge como uma importante oportunidade para desenvolver os territórios dos camponeses, cujo modelo de produção baseado nas culturas alimentares básicas de maneira agroecológica, se mostra como uma alternativa ao modelo hegemônico vigente do agronegócio, garantindo a Soberania Alimentar.

A produção sustentável pode ser definida como aquela que cria bens utilizando processos e sistemas que são não poluentes e que se utilizam de pouco insumos externos (CAMACHO et al., 2015). Uma parte fundamental da estrutura do PRONERA, particularmente no que diz respeito à sua lógica de desenvolvimento territorial, é a relação intrínseca com a dimensão natural do território (CAMACHO, 2014).

O Programa Nacional de Educação na Reforma Agrária (PRONERA) é um exemplo importante de Educação do Campo na esfera da política pública. Este programa foi criado no Brasil em 1998, como uma resposta aos esforços do movimento social e representantes de sindicatos rurais. O PRONERA pode ser considerado uma experiência inovadora, uma vez que foi implementado em um território que tem sido historicamente marcada pela exclusão social e pela ausência de políticas públicas na área da educação. Seu principal objetivo é fortalecer ambientes rurais como território de vida em todas as suas dimensões: econômica, social, política, cultural e ético. Tendo em vista a formação de milhares de jovens no campo, podemos afirmar que o programa tem ajudado a construir uma outra forma de desenvolvimento territorial em espaços rurais com base na equidade e sustentabilidade (BRASIL, 2011; CAMACHO, 2014).

A experiência de Educação do Campo do PRONERA analisados em nossa pesquisa foi o Curso Especial de Graduação em Geografia (CEGeo), resultado da cooperação entre INCRA ${ }^{1} /$ PRONERA/UNESP ${ }^{2} /$ ENFF $^{3}$. Camponeses assentados que participam dos movimentos socioterritoriais ${ }^{4}$, a maioria dos quais relacionados com a Via Campesina ${ }^{5}$, participaram deste curso que ocorreu entre anos de 2007 e 2011, alternando entre locais de ensino na UNESP, em Presidente Prudente - SP, e na Escola Nacional Florestan Fernandes, em Guararema - SP, como parte da metodologia da Pedagogia da Alternância ${ }^{6}$. O conhecimento adquirido no curso é

\footnotetext{
${ }^{1}$ Instituto Nacional de Colonização e Reforma Agrária.

${ }^{2}$ Faculdade de Ciências e Tecnologia (FCT) Universidade Estadual Paulista (UNESP).

${ }^{3}$ Escola Nacional Florestan Fernandes.

${ }_{5}^{4}$ Ações transformadoras realizadas por movimentos sociais no espaço.

${ }^{5}$ Movimento Camponês de organização mundial.

${ }^{6}$ Pedagogia da Alternância é uma metodologia de ensino-aprendizagem que alterna tempos-espaços educativos, sendo estes: tempo/espaço-universidade e tempo/espaço-comunidade.
} 
destinado a ajudar os camponeses com a sua militância em movimentos sociais, no seu desempenho nas escolas dos assentamentos, e na proposição de políticas públicas de desenvolvimento territorial rural, o que torna possível a envolver estes camponeses na construção de outra forma de desenvolvimento territorial no campo, que inclui a igualdade e a sustentabilidade (CAMACHO et al., 2015).

Levando isso em conta, o principal objetivo deste artigo é analisar a experiência de integração entre educação e sustentabilidade, no Programa Nacional de Educação na Reforma Agrária (PRONERA). Estamos interessados neste tema, porque o estudo das comunidades rurais tem sido negligenciado pelas universidades. Produções científicas sobre as comunidades rurais permanecem bastante precárias. Esta realidade começou a mudar quando movimentos camponeses socioterritoriais começaram a trazer esta e outras questões em discussão a nível nacional (SOBREIRO FILHO, 2011). No entanto, os estudos que se concentram em educação nas áreas rurais ainda são uma minoria, quando comparado com estudos sobre educação urbana. Por exemplo, em Novembro de 2014, encontramos 434 ocorrências do termo "Educação Rural" no banco de dados Scopus, e apenas 32 referem-se ao Brasil (CAMACHO et al., 2015).

No primeiro item, vamos resumir a história das desigualdades existentes entre campo e cidade no Brasil e pensar no esforço para que a Educação do Campo possa diminuir estas desigualdades. No segundo item, apresentaremos o PRONERA e estabeleceremos um diálogo entre o Manual de Operações do PRONERA (2011) e da literatura existente sobre o tema. No terceiro item, vamos explicar a metodologia adotada neste artigo. Depois disso, vamos apresentar os principais resultados.

\section{HISTÓRICO DA EDUCAÇÃO DO CAMPO NO BRASIL}

A criação de um novo projeto de Educação do Campo está relacionada com os esforços conjuntos de algumas entidades que formaram a Articulação Nacional em 1998, em favor da Educação Básica no Campo. As entidades que promoveram este movimento foram: a Conferência Nacional dos Bispos do Brasil (CNBB), o Movimento dos Trabalhadores Sem Terra (MST), Fundo das Nações Unidas para a Infância (UNICEF), Organização das Nações Unidas para a Educação, a Ciência e a Cultura (UNESCO), da Universidade de Brasília (UNB) e o Grupo de Trabalho da Reforma Agrária (GTRA). A primeira conferência chamada "Por uma Educação Básico do Campo" ocorreu em Luziânia - GO, em 1998.

O Movimento dos Trabalhadores Rurais Sem Terra defende a melhoria da qualidade da escola pública desde os anos de 1990. Sendo que seus militantes colaboraram na formação de professores para trabalhar em escolas do campo, em assentamentos e/ou acampamentos. Estas iniciativas contrastavam com o descaso histórico do governo brasileiro para com a escola pública do campo no Brasil. As escolas no campo eram constituídas de salas de aula multiseriadas, professores sem formação superior e falta de infraestrutura. O Movimento, então, desenvolve uma concepção de pedagogia denominada de "Pedagogia do Movimento". 


\section{ANAP

As experiências educacionais do MST passaram da escala local para a escala nacional. Esta proposta se desenvolveu e se transformou em um paradigma, denominado de Educação do Campo. Em 1998, um Encontro Nacional que reuniu movimentos sociais e sindicais camponeses, juntamente com religiosos e professores universitários, foi o marco inicial para transformar este paradigma educacional em política pública (CALDART, 2005; TARLAU, 2015; CAMACHO et al., 2015).

A primeira razão por trás da luta pela Educação do Campo no Brasil é a realidade existente de exclusão com relação aos habitantes do campo. A falta de acesso a uma educação que permita o desenvolvimento das comunidades no campo está relacionada com a história da estrutura agrária no Brasil baseada no latifúndio e na desterritorialização dos indígenas de suas terras tradicionais e das populações camponesas de sua terra de trabalho (CAMACHO et al., 2015). A realidade para os povos do campo tem sido sempre de uma educação que não ultrapassa as séries iniciais do ensino fundamental. Há ainda um grande número de analfabetos no campo. A educação sempre foi inacessível para estas populações excluídas. A leitura e a escrita são instrumentos de status e poder dentro de uma sociedade capitalista e são geralmente um privilégio das classes dominantes. Assim, as classes subalternas têm poucas oportunidades para dominar os códigos de culturas letradas (CAMACHO, 2014).

Uma pesquisa por amostragem realizada pelo Instituto Nacional de Colonização e Reforma Agrária (INCRA), em 2010, revelou que o acesso à educação continua sendo um grande desafio para populações rurais estabelecidas em todas as regiões do país. No que diz respeito aos dados sobre o ensino superior no Brasil, a região Norte tem 390.752 famílias assentadas, e menos de $1 \%$ com ensino superior concluído. A região Nordeste tem 302.513 famílias assentadas, mas menos de $1 \%$ tem diploma universitário. A região Centro-Oeste tem 138.000 famílias assentadas, destes, $1 \%$ possuem nível superior, e 1,33\% estão estudando. A região Sudeste tem 40.156 famílias assentadas, destes, 1,01\% tem curso superior concluído, e 1,16\% estão estudando. A região Sul tem 34.991 famílias assentadas: menos de 1\% com diploma universitário, e 1,09\% estão estudando (BRASIL, 2011).

Apesar de estudos e dados do censo mostrar uma expansão quantitativa no acesso escolar, as desigualdades sociais e regionais, bem como os níveis de analfabetismo, ainda são altos, especialmente, nas regiões Norte e Nordeste (PAIVA, 2004). De acordo com Andrade e Di Pierro (2004), aproximadamente $45 \%$ das crianças de 4 a 6 anos de idade e $10 \%$ entre 7 e 14 anos que vive em comunidades rurais não frequentavam a escola em 2000. Três em cada dez jovens ou adultos que vivem em áreas rurais eram analfabetos. Uma das principais causas destes números negativos é a inexistência de escolas próximas às residências das pessoas, a falta de transporte escolar, ou devido às condições de vida precárias de suas famílias exigem que eles comecem a trabalhar ou ajudar nas tarefas domésticas em uma idade muito precoce. A ausência de políticas públicas demonstra o tratamento desigual e discriminatório recebido pela população rural. Esta atitude negligente por parte do Estado tem levado a problemas educacionais de longa data, como o analfabetismo; crianças, adolescentes e jovens fora da escola ou sem escola; discrepâncias entre idade e série, repetição e fracasso; conteúdo inapropriado; problemas com a titulação, salários e carreiras dos professores; e uma oferta de 
escola que é geralmente reduzida para as quatro primeiras séries do ensino fundamental (ARROYO, 2013).

O movimento "Por uma Educação do Campo" foi criado para fazer frente a esta realidade de abandono por parte do Estado. Este movimento começou a exigir políticas públicas de instituições governamentais, bem como o financiamento para a investigação relacionada com questões educacionais em comunidades rurais. O silêncio, esquecimento, e até mesmo a falta de interesse em comunidades rurais em pesquisas sociais e educacionais é um ponto que estava se tornando preocupante. O movimento de Educação do Campo foi criado para relatar esse silêncio e o esquecimento das instituições governamentais, instituições de investigação de financiamento, programas de pós-graduação e estudiosos que estudam as questões sociais e educacionais (ARROYO, 2004).

A exclusão social e educacional dos habitantes das comunidades rurais tem de ser entendido historicamente. No Brasil, a força da ideologia dominante, que foi composta por oligarquias agrárias que prevalecem no país desde os tempos coloniais, tem defendido que era inútil e supérflua para os camponeses aprender a ler e escrever. $O$ argumento por trás disso era que a natureza do trabalho rural (produção de alimentos pelo cultivo da terra para sua subsistência e vender o excedente para a população urbana) não requer qualquer formação escolar. 0 próprio modo de vida dos camponeses era, a priori, a razão para negar-lhes o acesso à educação (ARROYO, 2004; CAMACHO, 2014).

Apesar de a educação ser reconhecida como um direito humano desde os anos 1980 e que a promoção de uma educação de alta qualidade é o segundo dentre os oito objetivos para o desenvolvimento no milênio para uma sociedade mais justa e sustentável (PNUD, 2014), este reconhecimento não atingiu áreas rurais brasileiras. Moradores de comunidades rurais foram totalmente excluídos desta conquista; este direito só manteve-se no nível abstrato do conceito de cidadania e não atendeu as necessidades específicas e concretas da realidade das comunidades rurais (ARROYO, 2004; CAMACHO et al., 2015). Portanto, a Educação do Campo é uma condição fundamental para que a população rural possa exercer sua cidadania (FERNANDES; MOLINA, 2004).

Em suma, a marginalização social e educacional vivida pelos moradores das comunidades rurais, devido a falta de políticas públicas voltadas para a sua realidade, engendrou a emergência de lutas de sujeitos coletivos que reagiram diante dessas situações sociais. Dentre estas lutas, destaca-se: a luta pela terra e pela reforma agrária que desencadeou a luta pela Educação do Campo (CAMACHO et al., 2015).

\section{O PROGRAMA NACIONAL DE EDUCAÇÃO NA REFORMA AGRÁRIA - PRONERA}


A história da Educação do Campo está diretamente relacionada à consolidação de uma política pública ${ }^{7}$, ao passo que a primeira grande conquista na Educação do Campo foi o PRONERA. De acordo com Molina (2004), o PRONERA é o pilar teórico e prático da Educação do Campo. O PRONERA tem como objetivo a criação de uma educação que está devidamente adaptado à lógica do trabalho e da cultura no campo, bem como a busca de outra forma de desenvolvimento mais sustentável socialmente e ambientalmente. No PRONERA, as práticas educativas envolvem, os seus sujeitos, ao seu território, a sua forma de organização do trabalho, e a sua cultura, buscando o estabelecimento de outro modelo de desenvolvimento, que seja socialmente justo e ecologicamente sustentável.

De acordo com o Manual de Operação do PRONERA (2011), o PRONERA é uma política pública cujo principal objetivo é fortalecer os territórios rurais em todas as suas dimensões: ambiental, econômica, social, política, cultural e ética. O programa foi criado em 1998 como resultado do esforço feito por representações de movimentos sociais e sindicatos camponeses. A criação deste programa permitiu milhares de trabalhadores, jovens e adultos das áreas de reforma agrária, acessarem o seu direito aos diferentes níveis de ensino.

A inserção da Educação do Campo na agenda pública ocorreu graças aos movimentos socioterritoriais camponesas, especialmente, o Movimento dos Trabalhadores Rurais Sem Terra (MST). As experiências educativas alternativas que estavam ocorrendo em acampamentos e assentamentos começaram a ser organizados em seminários e encontros regionais e nacionais durante a segunda metade da década de 1990 (ANDRADE; DI PIERRO, 2004; TARLAU, 2015). A Conferência Nacional da Educação Básica do Campo ocorreu em 1998. O objetivo dessa conferência foi o de sensibilizar os órgãos governamentais e a sociedade, em geral, sobre a importância da implementação de políticas públicas de educação adequadas às especificidades das populações do campo (CAMACHO, 2014; CAMACHO et al., 2015).

O PRONERA compreende hoje as ações de alfabetização de jovens e adultos; escolarização nos níveis fundamental, médio, superior e pós-graduação; formação continuada de professores; formação técnico-profissional para a saúde; a comunicação; a produção agropecuária e a gestão do empreendimento rural. Todas estas modalidades de educação estão pautadas em metodologias de ensino adequadas a realidade sociocultural do campo (ANDRADE; DI PIERRO, 2004).

Para a atualização dos dados, o PRONERA lançou a Segunda Pesquisa Nacional de Educação na Reforma Agrária (II PNERA). Esta foi uma pesquisa realizada em parceria com o Instituto Nacional de Estudos e Pesquisa Anísio Teixeira (MEC-INEP) e o Instituto de Pesquisas Aplicadas (IPEA). A pesquisa teve como objetivo caracterizar a demanda educacional e diagnosticar a situação do ensino ofertado nos assentamentos da Reforma Agrária. O resultado da pesquisa é que no período entre 1998 a 2011 foram realizados 320 cursos do PRONERA por meio de 82 instituições de ensino em todo o país, sendo 167 de Educação de Jovens e Adultos

\footnotetext{
${ }^{7}$ Elas significam a materialização dos direitos presentes no artigo 60 da Constituição Federal Brasileira de 1988, entre os quais, encontramos educação (MOLINA, 2012).
} 


\section{ANAP

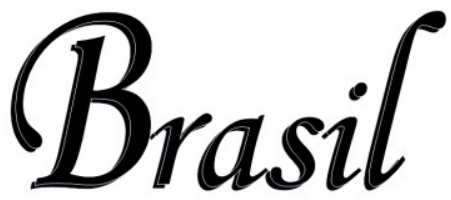 \\ ISSN $1984-3240$ \\ V. 9, n. 14}

Fundamental, 99 de nível Médio e 54 de nível Superior. Os cursos foram realizados em 880 municípios, em todas as unidades da federação (MST, 2015). Vejamos a Figura 1:

Figura 1: Cursos do PRONERA por município de realização (1998-2011)

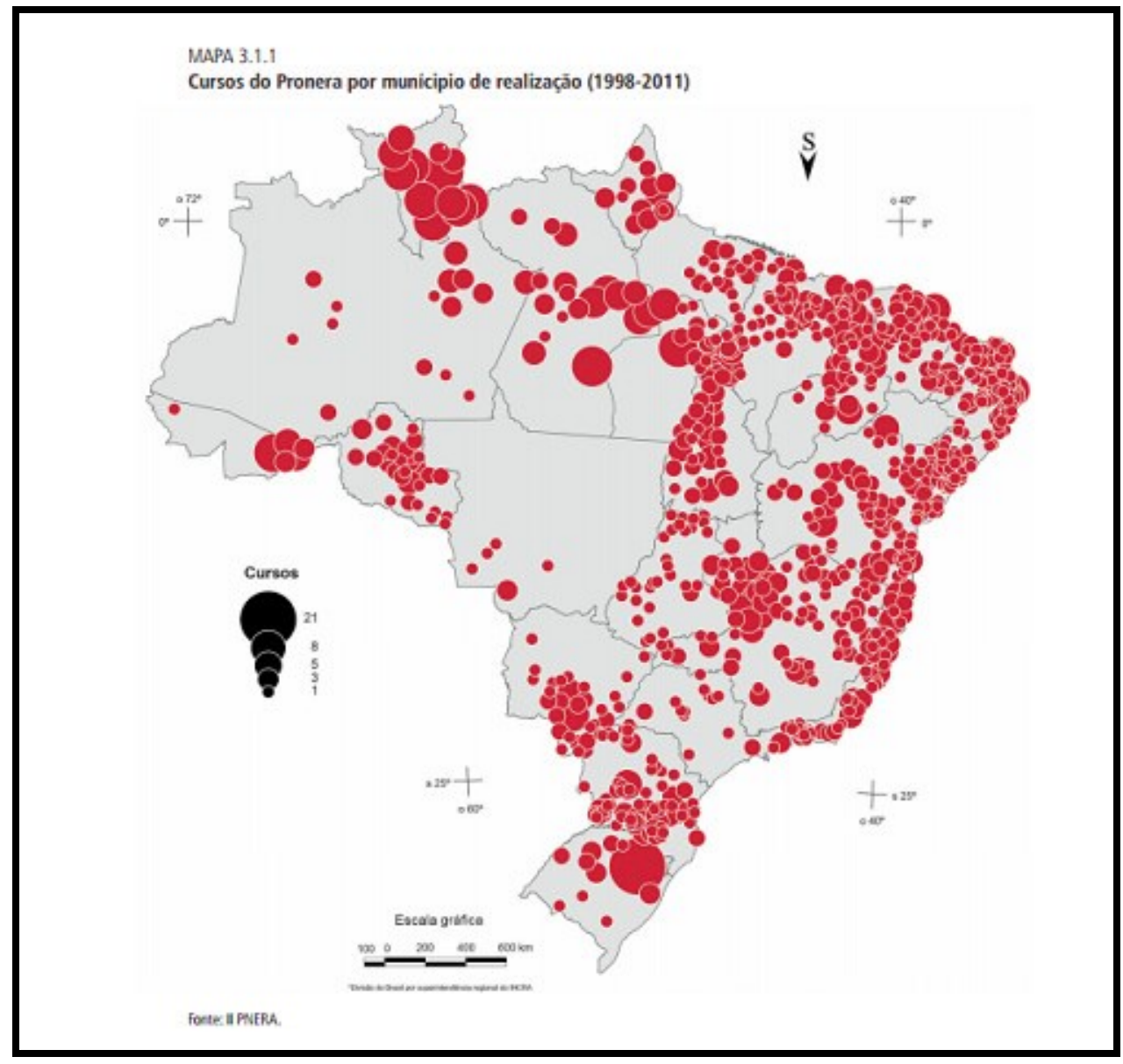

Fonte: II PNERA, 2015.

Em termos de política pública específica, por meio da interação com os movimentos sociais camponeses, a experiência do PRONERA conseguiu se relacionar com a extrema diversidade de situações presentes no campo brasileiro. Diversidade esta que envolve desde a heterogeneidade dos sujeitos sociais do campo, bem como a diversidade das condições culturais, ambientais, geográficas e de organização da produção agrícola. Esta característica do PRONERA somente foi possível devido à interlocução direta que foi travada com os protagonistas deste processo (MOLINA, 2004).

O processo para a aprovação dos projetos é feito da seguinte maneira, as instituições de ensino encaminham o projeto para a Superintendência Regional do INCRA, onde a equipe do PRONERA o avaliará. Depois, o projeto é encaminhado à Coordenação-Geral de Educação do Campo e Cidadania para análise da Comissão Pedagógica Nacional (CPN) (BRASIL, 2011). A Comissão Pedagógica Nacional cuida para que os projetos se orientem por cinco princípios 
fundamentais que compõe o PRONERA: a inclusão, a participação, a interatividade, a multiplicação e a parceria (ANDRADE; DI PIERRO, 2004).

A inclusão é o princípio que defende a ampliação das condições de acesso à educação; A participação é a garantia que os beneficiários e seus parceiros têm participarem da elaboração, execução e avaliação dos projetos; $A$ interatividade diz respeito à forma como as parcerias entre órgãos governamentais, instituições de ensino superior, movimentos sociais e sindicais e comunidades assentadas estabelecem um diálogo permanente; A multiplicação diz respeito à ampliação não só o número de alfabetizados, mas também de monitores, profissionais e agentes mobilizadores que podem dar continuidade aos processos educativos; A parceria é a condição para a realização das ações do PRONERA. São considerados parceiros do programa: as Instituições de ensino, pesquisa e extensão, públicas e privadas sem fins lucrativos e fundações de apoio; as secretarias municipais e estaduais de educação; Os movimentos sociais e sindicais representativos do público beneficiário (BRASIL, 2011).

\section{METODOLOGIA}

Para escrever este artigo, como um primeiro passo, nós revisamos a literatura sobre Educação do Campo dialogando, sobretudo, com o Manual de Operações do PRONERA publicado em 2011. Como segundo passo, analisamos o Projeto Político-Pedagógico do Curso Especial de Graduação em Geografia (CEGeo ). Na terceira etapa, foram realizadas 04 estudos de campo. Por meio da observação participante, os alunos foram entrevistados e utilizando a metodologia das fontes orais aplicamos um questionário semiestruturado para os sujeitos envolvidos nos procedimentos operacionais do curso: os educadores-professores, estudantes, coordenadores, monitores etc.

Também é importante ressaltar que esses quatro estudos de campo foram realizados nos seguintes períodos: o primeiro foi realizado de 10 de janeiro de 2010 a 20 de fevereiro de 2010, na Faculdade de Ciências e Tecnologia da Universidade Estadual Paulista (UNESP), em Presidente Prudente, SP; o segundo foi realizado em julho de 2010, na Escola Nacional Florestan Fernandes (ENFF), em Guararema, SP; o terceiro foi realizado de 10 de janeiro de 2011 a 07 de fevereiro de 2011, na Faculdade de Ciências e Tecnologia da Universidade Estadual Paulista (UNESP), em Presidente Prudente, SP; e o último foi realizado em julho de 2011, na Escola Nacional Florestan Fernandes (ENFF) em Guararema, SP.

\section{O CURSO ESPECIAL DE GRADUAÇÃO EM GEOGRAFIA (CEGEO)}

Este curso foi organizado a partir de uma parceria construída entre a Via Campesina - Brasil; a Escola Nacional Florestan Fernandes - ENFF; a Faculdade de Ciências e Tecnologia da Universidade Estadual Paulista Júlio Mesquita Filho - UNESP - Campus de Presidente Prudente; o Ministério do Desenvolvimento Agrário - MDA e Instituto Nacional de Colonização e Reforma Agrária - INCRA por meio do Programa Nacional de Educação na Reforma Agrária PRONERA. 
A turma nomeada pelos educandos-camponeses de Milton Santos, contava inicialmente, em 2006, com 60 estudantes, no qual destes se formaram 46 em 2011. Todos representando movimentos sociais ligados a Via Campesina - Brasil: MST (Movimento dos Trabalhadores Rurais Sem Terra), MPA (Movimento dos Pequenos Agricultores), MAB (Movimento dos Atingidos por Barragens), MMC (Movimento de Mulheres Camponesas) e PJR (Pastoral da Juventude Rural), RACEFAES (Rede de Amigos e Colaboradores das Escolas Família Agrícola do Espírito Santo), MTST (Movimento dos Trabalhadores Sem Teto de São Paulo),EDUCAFRO (Educação e Cidadania de Afro-descedentes e Carentes)e o MCP (Movimento Consulta Popular).

Este curso teve como metodologia a Pedagogia da Alternância, ou seja, alternava o entre os territórios educativos (ANTUNES-ROCHA; MARTINS, 2012) do Tempo Escola (TE) com o Tempo Comunidade (TC). Sendo que os Tempos Escolas ocorriam em janeiro e fevereiro na Universidade Estadual Paulista em Presidente Prudente/SP e em julho e agosto na Escola Nacional Florestan Fernandes - ENFF em Guararema/SP.

Os objetivos dos cursos em nível superior do PRONERA são de garantir a formação profissional para qualificar as ações dos sujeitos e disponibilizar, em cada área de Reforma Agrária, recursos humanos capacitados que contribuam para o desenvolvimento socialmente justo $\boldsymbol{e}$ ecologicamente sustentável (BRASIL, 2011). Conforme o Manual de Operações do PRONERA: "Os cursos devem possuir uma sólida formação teórica e contemplar as situações da realidade dos assentados a fim de que os educandos encontrem soluções para os problemas e, simultaneamente, capacitem-se". (2011, p. 72, grifo nosso).

A partir dessa compreensão o curso está sedimentado em 05 princípios fundamentais referentes à sua proposta pedagógica: a docência como princípio articulador das atividades pedagógicas; a sólida formação teórica; o compromisso profissional com a realidade e a experiência prática como princípio articulador das atividades; a pesquisa como princípio formativo e a educação como estratégia para o desenvolvimento territorial sustentável.

Os conhecimentos adquiridos no bacharelado e licenciatura objetivam formar Geógrafos e Professores que auxiliem no desenvolvimento territorial de sua comunidade, formando professores e geógrafos militantes dos movimentos sociais. A relação com os movimentos sociais camponeses demonstra, entre outros aspectos, as seguintes características do Curso: a relação direta estabelecida com a realidade na qual estão vinculados estes sujeitos; o modelo de gestão tripartite que revela o caráter democrático do PRONERA; o contato direto com as necessidades reivindicadas pela sociedade civil organizada; a possibilidade de instrumentalização dos sujeitos para que transformem a sua realidade tendo como veículo um modelo de educação emancipatório; a possibilidade concreta de construção de uma outra forma de desenvolvimento com sustentabilidade proposta e efetivada por estes sujeitos.

A partir de trabalho de campo na UNESP (Presidente Prudente - SP) e na Escola Nacional Florestan Fernandes (Guararema - SP) pudemos enxergar que os estudantes-militantes dos movimentos socioterritoriais camponeses entendem que o curso de geografia lhes auxiliam em vários aspectos em suas lutas para um desenvolvimento territorial menos desigual e mais sustentável, compreendendo as relações naturais e sociais dos territórios camponeses. 
Para quem atua na militância, se faz necessário planejar a organização dos territórios conquistados, e a Geografia traz elementos que ajudam a pensar este processo. Ela possui um conjunto de ferramentas que possibilita refletir acerca da construção de outras formas de assentamento. Esta é uma tarefa que requer analisar a paisagem do território conquistado: o relevo, o solo, a hidrografia, a infraestrutura, se a localização do assentamento está no fundo de vale ou topo da montanha, se tem acesso a água etc. Estas configurações territoriais implica em influências sobre, por exemplo, acesso a energia elétrica e às formas de escoamento da produção. O Movimento quer pensar novas configurações de organização para os assentamentos, quer pensar novas formas de organização do espaço. Neste sentido, a Geografia auxilia o Movimento para uma forma racional de pensar o espaço, de planejar o território conquistado, levando em consideração os aspectos naturais: fundo de vale, topo, acesso à água etc., para a construção de outras formas de assentamento mais eficientes. Dito de outra maneira:

Então um dos grandes dilemas que se tem é como tu configurar novos designes de assentamentos, como tu construir formas organizativas olhando pra paisagem, olhando pro relevo, olhando pra infraestrutura local. [...] E a Geografia ela cai feito uma luva pra esse processo, de pensar o espaço, de pensar o território, de planejar esse território. [...] Temos que conceber assentamentos com desenhos diferentes de que tem hoje. Porque você vai pegar (...) assentamentos da década de 80 , até mesmo meados da década de 90,95 , [...] se dividia os lotes, sem critério nenhum. Sem critério se tá no fundo de vale, se tava no topo, se ia ter acesso a água ou não ia ter. [...] O primeiro assentamento planejado que teve foi em 97,98 , foram três assentamentos que ficam na região de Bagé, que teve no mínimo uma racionalidade na hora de dividir os lotes. Que levou em conta um pouco o perfil do solo, essa questão topografia, acesso à água, aonde que ia ser estrada, porque que ia ser ali, porque que não ia. Ou seja, é uma forma racional de pensar um espaço, né. (LT, UNESP, Jan. 2011).

Os estudantes pesquisaram temas importantes em suas monografias que pudessem auxiliar de maneira direta sua atuação em sua comunidade. Com relação a produção com sustentabilidade, a estudante-camponesa, $\mathrm{Nc}$, focou em sua pesquisa a questão da Soberania Alimentar e Energética com a Agroecologia, ou seja, a importância da produção de alimentos saudáveis e sem agrotóxicos e a utilização do biodigestor para a produção de gás em seu assentamento.

Então, meu tema é "Soberania Energética e Alimentar" [...] e a experiência assim que existe, é o biodigestor, que é o gás de cozinha, onde se aproveita as fezes dos porcos pra fazer o gás e, também, serve de biofertilizante. Ao invés de ser o veneno lá, as ureias compradas na loja [...]. Outra questão, também, trabalhar um pouco voltado na agroecologia, né, como que se liberta do veneno e dos adubos, dos fertilizantes, produzindo e se libertando 
deles, como que poderia nós produzir mais em forma de agroecologia. (UNESP, Jan. 2010).

Também, com relação a produção sustentável, o estudante-camponês e militante-técnico do MST/RS, LT, decidiu pesquisar acerca da produção do arroz orgânico no assentamento Filho Sepé/RS, por entender que este é um elemento fundamental que influencia na multidimensionalidade desse território estudado. Para tal análise, tem tentado absorver o aprendizado científico-acadêmico para ler à realidade. Sendo que sua inserção a esta realidade Ihe permite fazer a análise de maneira muito mais aprofundada unindo teoria-prática.

Então, o projeto ele ocorre dentro do assentamento Filho Sepé mesmo, é tentar identificar as potencialidades $e$ os limites da produção do arroz orgânico dentro desse assentamento. [...]. Então, para contribuir com o assentamento eu procurei desenvolver uma monografia que tivesse um pouco essa importância para $\boldsymbol{a}$ comunidade local. [...]. (UNESP, Jan. 2011).

Nesta perspectiva, a educanda Adr do Curso Especial de Graduação em Geografia, moradora do Assentamento Itapuí, em Nova Santa Rita, no Rio Grande do Sul, descreve a importância que tem o seu projeto de monografia para a sua intervenção em seu assentamento. Seu projeto de pesquisa vai ao encontro das necessidades de se pensar um modelo de produção alternativo camponês ao modelo da monocultura e produção com agrotóxicos.

[...] O meu projeto da monografia eu escolhi sobre a produção agroecológica dentro do assentamento, do meu assentamento. Porque lá na nossa região a gente trabalha por grupos gestores, então a gente tem o grupo gestor das hortas, o grupo gestor do leite e o grupo gestor do arroz. Esses grupos gestores são tudo grupo gestor voltado a agroecologia, que se produz de forma orgânica sem nenhum uso de veneno. [...]. (ENFF, Jul. 2010).

Outra pesquisa ligada a questão da produção: soberania alimentar, energética e popular, é a do militante do MPA/ES, Als. Ele reafirma que a tomada de decisão do seu tema está relacionada com uma tomada de decisão coletiva do Movimento. Vai discutir em sua monografia a questão da importância das mini-usinas de beneficiamento do leite Este seria mais um mecanismo de resistência camponesa.

[...] Então, o meu tema hoje é essa questão do campesinato, agroindústria e mercado capitalista, fazendo um estudo da questão da produção de leite no município numa perspectiva da implantação de mini-usinas de beneficiamento de leite. [...]. É uma estratégia de sobrevivência, então, na perspectiva da construção da soberania alimentar, energética, da soberania popular. [...]. (ENFF, Jul. 2010). 
O movimento dos camponeses produziu uma luta para obter o desenvolvimento sustentável da produção agrícola. Assim, a incorporação do tema na estratégia dos camponeses aumentou. Consequentemente, a educação tem sido o plano principal, e o PRONERA e o GEGeo são as principais ferramentas para este fim.

A formação de 400 mil jovens e adultos assentados e/ou acampados da reforma agrária e a capacitação de cerca de 300 profissionais para atuarem na Assessoria Técnica, Social e Ambiental nos Assentamento de Reforma Agrária e na agricultura familiar camponesa, demonstra a efetivação de seu objetivo de construção de um desenvolvimento territorial rural economicamente justo e ambientalmente sustentável.

Os cursos do PRONERA tem a educação como uma estratégia para o desenvolvimento sustentável. E a formação técnica e pedagógica pelo CEGeo permitirá que os estudantes possam contribuir para o desenvolvimento com sustentabilidade em sua comunidade. Esta experiência nos mostra a realização do princípio fundamental do desenvolvimento territorial sustentável, que é a de "pensar global, agir local". Por isso, a relevância e a legitimidade destas propostas educacionais para a sustentabilidade são reforçadas, em conjunto com a participação de organizações da sociedade civil em movimentos sociais. Apesar de o PRONERA ser uma experiência estritamente local, ele ainda pode se espalhar para outras escalas dentro da rede mundial.

Assim, as experiências educacionais no campo que estão sendo desenvolvidas por PRONERA nos permite visualizar o papel da sociedade civil organizada através de movimentos camponeses sociais, no desenvolvimento de uma política pública para construir uma nova visão sobre educação, democracia, desenvolvimento e o meio ambiente.

\section{REFERÊNCIAS}

ANDRADE, Márcia Regina; DI PIERRO, Maria Clara. A construção de uma política de educação na reforma agrária. In: ANDRADE, Marcia Regina; PIERRÔ, Maria Clara Di; MOLINA, Mônica Castagna; JESUS, Sonia Meire Santos Azevedo de et al (Orgs.). A educação na Reforma Agrária em perspectiva. São Paulo: Ação Educativa; Brasília: PRONERA, 2004a. p. 19-54.

ARROYO, Miguel Gonzalez. A educação básica e o movimento social do campo. In: ARROYO, Miguel G.; CALDART, Roseli S.; MOLINA, Mônica C. (Org.). Por uma educação do campo. Petrópolis: Vozes, 2004. p. 67-86.

BRASIL. Ministério do Desenvolvimento Agrário - MDA. Instituto Nacional de Colonização e Reforma Agrária - INCRA. Programa Nacional de Educação na Reforma Agrária (PRONERA). Manual de Operações do Pronera. Brasília: MDA/INCRA, 2011.

CALDART, Roseli Salete. Momento atual da educação do campo. Disponível em: <http://www.nead.org.br/artigodomes/imprime.php?id=27>. Acesso em: 02 jul. 2005. 


\section{ANAP

CAMACHO, Rodrigo Simão. Paradigmas em disputa na educação do campo. 2014. 806 p. Tese (Doutorado em Geografia) - Faculdade de Ciências e Tecnologia, Universidade Estadual Paulista, Presidente Prudente, 2014.

CAMACHO, Rodrigo Simão et al. Evaluation of the relationship between education and sustainability in peasant movements: the experience of the national education program in agrarian reform. Evaluation and Program Planning, v.1, p.1 - 23, 2015.

FERNANDES, Bernardo Mançano; MOLINA, Mônica Castagna. O campo da educação do campo. In: MOLINA, Mônica Castagna; JESUS, Sonia Meire Santos Azevedo de (Org.). Por uma educação do campo: contribuições para a construção de um projeto de educação do campo. Brasília: Articulação Nacional "Por Uma Educação do Campo", 2004. p. 53-91. (Por Uma Educação do Campo, 5).

MOLINA, Mônica Castagna. Pronera como construção prática e teórica da educação do campo. In: ANDRADE, Marcia Regina; PIERRÔ, Maria Clara Di; MOLINA, Mônica Castagna; JESUS, Sonia Meire Santos Azevedo de et al (Orgs.). A educação na Reforma Agrária em perspectiva. São Paulo: Ação Educativa; Brasília: PRONERA, 2004. p. 61-85.

PNUD. Sobre o desenvolvimento humano. Disponível em: <http://hdr.undp.org/en/humandev>. Acesso em: 01 nov. 2014.

SOBREIRO FILHO, José. Ocupações de terra no Brasil (1988-2010): uma leitura geográfica e a conjuntura política da luta pela terra. Geographos, v. 2, n.14, p. 1-26, 2011.

TARLAU, Rebecca. Education of the countryside at a crossroads: rural social movements and national policy reform in Brazil. The Journal of Peasant Studies, p. 1-21, 2015. Disponível em: <http://www.tandfonline.com/loi/fjps20>. Acesso em: 21 abr. 2015. 